\title{
Turbocharged gasoline engine with separate exhaust valve configuration (TwinAV) - A simulation study
}

\author{
Andreas Gotter, Alexander Gotter \\ gofficient UG, Aachen, Germany
}

\begin{abstract}
After decades of part-load optimization, increasing demands on maximum efficiency of the combustion engine are bringing technologies such as exhaust heat utilization into focus, particularly as the best operation point can be reached more often due to hybridization and new transmission concepts.

Turbocharging is a common and simple method to utilize the exhaust heat of an internal combustion engine. However, static turbocharging exhibits the drawback of exhaust gas backpressure and thus increased residual gas mass in the cylinder.

A promising concept to increase optimum efficiency is found in the TwinAV concept, which assigns valve individual cam timing and exhaust configuration. This concept has the capability to reduce the static backpressure in the load exchange loop, while enabling unlimited turbocharged operation.

Within this work, a 1-D simulation model was adapted to an existing 4-cylinder gasoline TC engine. Subsequently the TwinAV concept was applied to this engine model and results were compared.

In this research two possible layouts have been considered: The first layout is designed for full engine operation over the entire engine speed and load range. This layout demonstrates that the specific fuel consumption can be reduced by up to $6.4 \%$ at 23 bar IMEP, whereby a reduction of $2.5 \%$ could be achieved at 15 bar IMEP.
\end{abstract}

The second layout was designed for steady-state operation with shorter cam event lengths. This layout shows a theoretical potential for up to $10 \%$ efficiency gain. An initial cost estimate shows that the costs per gram of $\mathrm{CO}_{2}$ saved are quite attractive.

\section{Keywords}

Internal Combustion Engine (ICE), gasoline engine, TwinAV, efficiency gain, waste heat recover (WHR), Miller, turbocharging, cam timing, variability

\section{Introduction}

To optimize the maximum efficiency of a gasoline engine, the fundamental thermodynamic behavior of the engine should be considered [1]. The theoretical efficiency of an internal combustion engine is given by compression ratio and isentropic coefficient [2]:

$$
\eta_{I C E}=1-\frac{1}{\varepsilon^{k-1}}
$$

Eq. 1: Efficiency of internal combustion engine

When comparing the theoretical efficiency with a Carnot-process, it appears, that despite very high 
peak temperatures, a comparative low efficiency is reached.

$$
\eta_{C}=1-\frac{T_{\text {sink }}}{T_{\text {source }}}
$$

Eq. 2: Efficiency of Carnot process

A look into the T-s-diagram reveals, that not only the peak temperature, but also the average temperature for heat release is sufficiently high for reaching decent efficiencies. The reason for wasted efficiency is the high exhaust temperature, which still contains a lot of unused exergy. In general, a higher compression ratio would resolve this, but as compression ratio of the gasoline engine is limited by the knock limitation, other ways must be found.

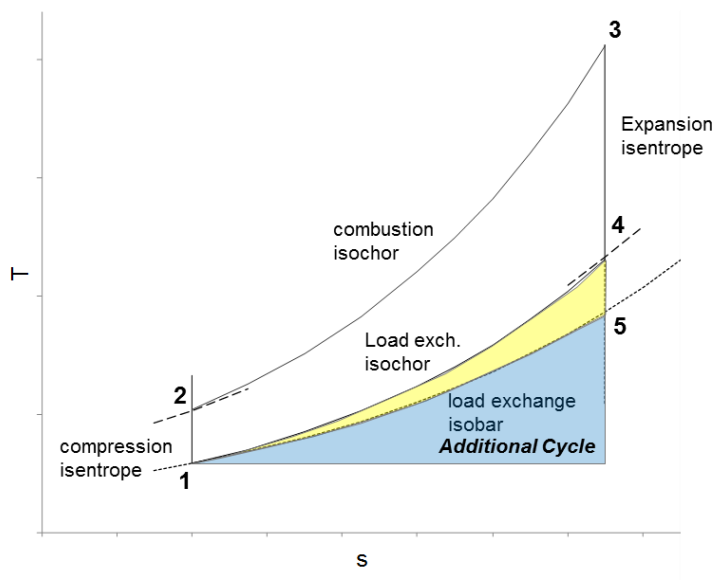

Figure 1: extended expansion for Miller-process and Twin-AV-process

The T-s-diagram in figure 1 illustrates the efficiency of a thermodynamic process. The energy is released during the combustion phase, going from point 2 to 3 . The usual load exchange happens isochoric from 4 to 1 . The area below the line 4-1 is wasted exergy. It is evident, that an isobar load exchange would increase the efficiency as less exergy is wasted and the best case would be an isothermal load exchange.
The first part (yellow area in figure 1) can partly be recovered by the turbocharging principle presented in this paper. The second part (blue area in figure 1) needs an additional cycle with either ORC or other Rankine cycle $[3,4,5]$. This Rankine cycle could also be integrated into the combustion engine itself [6]. However, also a Joule process like [7] as well as a thermoelectric generator like [8] is possible.

Step to isobar expansion

To achieve an isobar expansion within the combustion engine, we would need an expansion ratio of $>30$ (compare Eq.1), which cannot be reached by VCR, Millering or any other classical method.

For illustration, the $p$-V-diagram is shown principally in figure 2 , whereas the upper part shows the potential gain by Millering.

The picture below shows the idea, we want to discuss in detail now. The cylinder air charge is conducted to an expansion turbine at constant volume. The expansion now happens during increasing volume. In this state a larger fraction of the exhaust exergy can be made available.

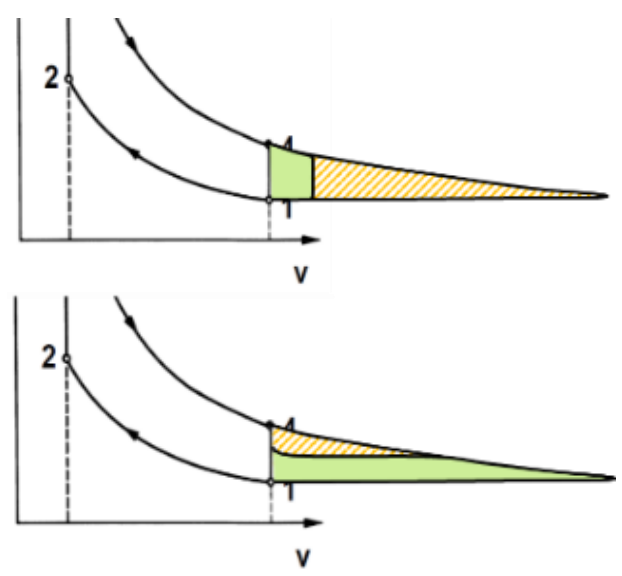

Figure 2: $\mathrm{p}$-V-Diagram of internal combustion engines, highlighting Miller and TwinAV benefits 


\section{Method - Twin AV concept}

The idea of the Twin AV concept is to avoid the load exchange work induced by the backpressure of the exhaust gas upstream turbine. This was previously developed in 2005 [9], but not further investigated since.

The principle idea is to use the first impulse of exhaust gas when the exhaust valve opens. At the time of exhaust valve opening, the cylinder pressure is typically about 6 to 12 bar, depending on the level of current boosting.

In order to make use of this first impulse, the Twin $\mathrm{A} V$ concept assigns one manifold to each exhaust valve, where only one manifold is connected to the turbine, as shown in figure 3 .

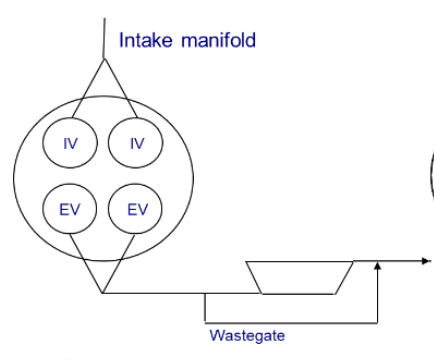

Conventional

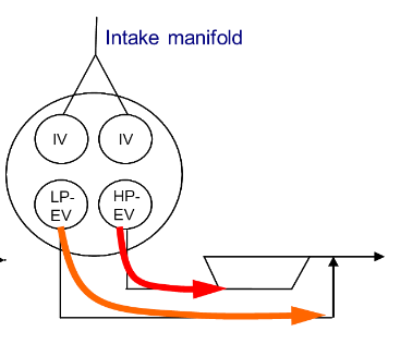

Twin AV
Figure 3: Concept layout of TwinAV system

The ingenious principle now is to actuate both exhaust valves in a time sequence successively rather than at the same time. At first, only the high pressure valve is opened. Displaced therefrom the second exhaust valve is opened short after as principally shown in figure 4

The effect of this actuation is, that the high impulse at the first valve opening is going completely through the first valve, which is connected to the turbine. This impulse contains - depending on operation point and backpressure $-60-80 \%$ of the exhaust mass flow and more than $75 \%$ of the exhaust exergy.

All this can happen, when the piston is still in a position close to its bottom dead center (BDC), thus, no load exchange work happens during this exhaust impulse harvesting.

The idea now is to close the first exhaust valve and open the second exhaust valve as long as the piston is just a few degree away from its BDC. After some further degree for valve switch and flow, the backpressure inside the cylinder is roughly equal to the pressure downstream turbine, which is generated by catalyst and muffler backpressure over ambient. For this reason, most of the load exchange work due to turbine backpressure can be avoided.
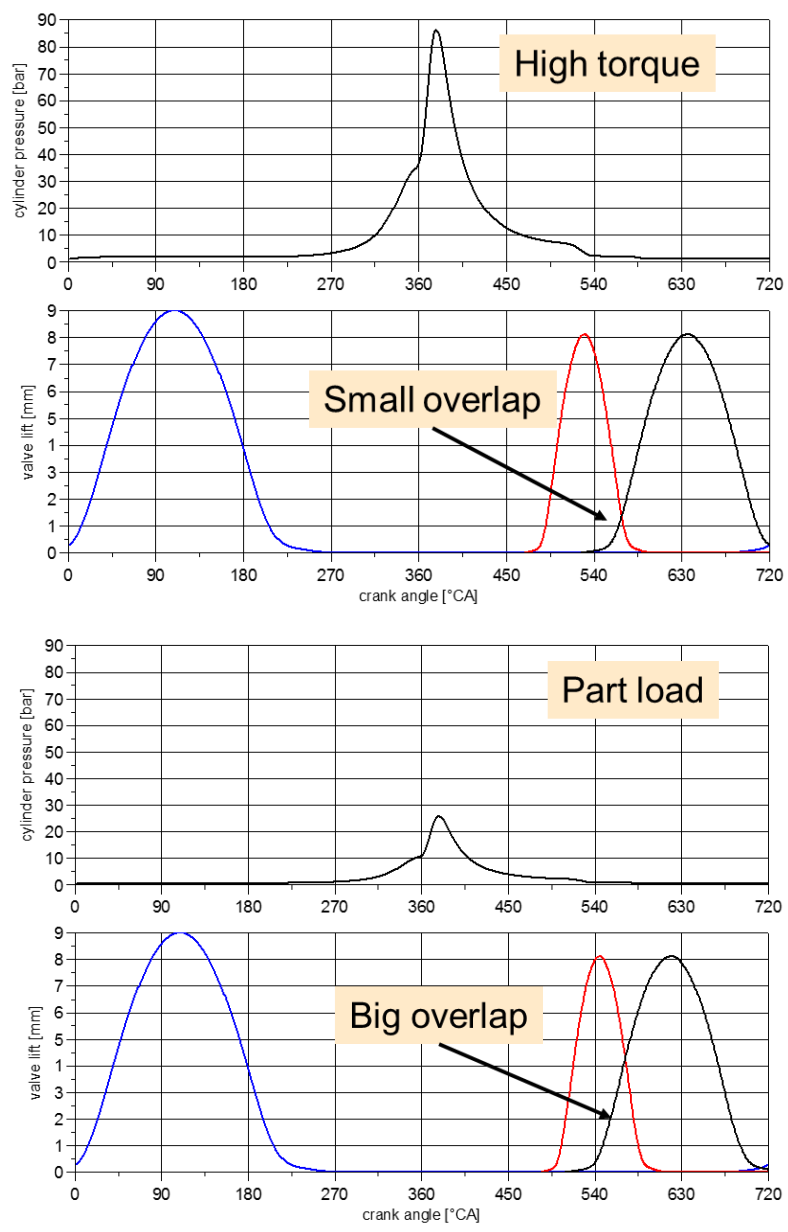

Figure 4: typical control diagram for TwinAV exhaust valve timing for high load and part load 
Assuming a configuration with an unmodified turbocharger, we can only achieve max. $75 \%$ of the turbine power, which would be too little for sufficient turbocharging, as the mass flow through the turbine is lower in this configuration in comparison to a baseline engine. However, this can be compensated by a layout change of the turbine as discussed in the next chapter.

In general, the usage of resonance pipes in the high-pressure manifold could realize additional potential by using the returning under pressure to discharge the cylinder even more at high pressure valve closing. However, this optimization is not further considered here to keep the concept as simple as possible.

\section{Turbine layout}

The requirements for the exhaust gas expansion turbine differ from the requirements of a classical turbocharged engine, as the exhaust mass flow though the turbine is $\sim 25 \%$ less. However, a higher backpressure upstream turbine does not have negative influence on the engine thermodynamics anymore. The backpressure during the exhaust stroke is now primarily influenced by the pressure inside the low-pressure manifold in this configuration. Thus, the pressure ratio at the turbine can be designed higher in comparison to classical turbocharging, resulting in the same or even higher available power output at the turbine shaft.

For illustration, figure 5 shows the pressure ratio and mass flow for a typical low-end-torque operation point. The classical configuration for gasoline engines with wastegate actuation indicates $100 \%$ mass flow through turbine and no massflow through the wastegate in this operation point. Due to the (in comparison to TwinAV) high mass flow, a relatively low-pressure ratio is sufficient to achieve the turbine power - and also reasonable to keep the backpressure low. With increasing engine speed the backpressure rises, but the increasing turbine power is not needed, it is typically wasted through the waste-gate.

The layout design of a turbocharger for TwinAV shows roughly half the cross-section of a conventional turbocharger. The first effect of this is increased backpressure, in this example approximately 2 bar. Next, the mass flow through the HP turbine slightly decreases, but it is still 45 $\mathrm{g} / \mathrm{s}$ in the shown example. Thus the available power at the turbine also increases (gray line). It is evident, that the available power could be increased much further by selecting an even smaller turbine inlet cross-section. However, the shown layout is sufficient and a good compromise for a wide engine speed range. Only for steadystate applications a smaller cross-section is possible. In this case, the excessive turbine power must be made available by an additional electrical generator or drivetrain.

The development of additional components such as a generator can be quite cost-intensive, so this is not investigated further here. Alternatively the combination with Miller-based cam timings could also partly handle excessive power. 


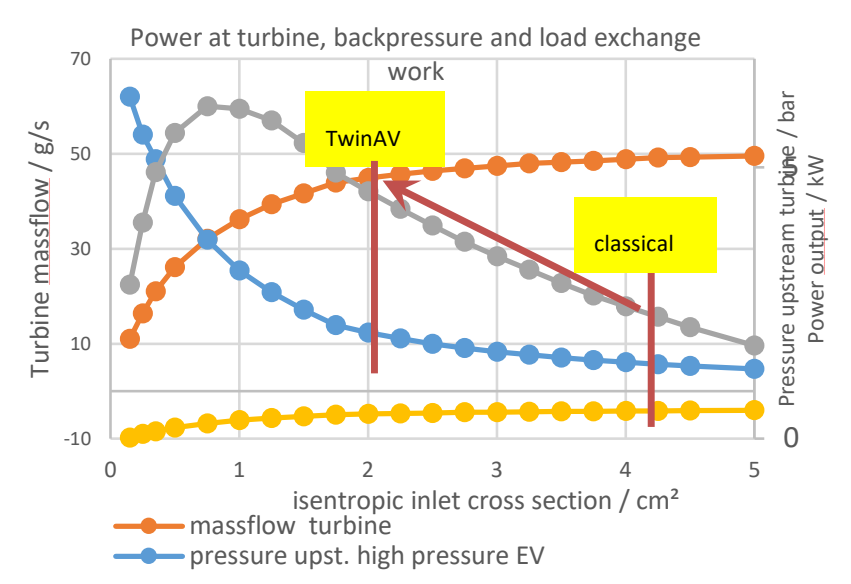

Figure 5: Pressure ratios and mass flow at the turbine for classical and TwinAV concept (generalized view)

\section{Cam timings}

There is a wide spread of technologies available for achieving variable cam timing $[10,11]$.

Even variabilities with just one camshaft are commercially available with the Cam-in-Cam system [11].

Ideally, the combustion engine is being operated with 3 cam phasers: The first cam phaser controls the inlet cam and influences base volumetric efficiency and scavenging rate.

The second cam phaser controls the high pressure exhaust valve and the valve overlap cross-section relative to the low-pressure exhaust valve. By this, the boost pressure can be controlled as shown in figure 4 . Herein, low overlap means more mass flow through the turbine and thus higher boost pressure, whereas high valve overlap results in lower boost pressure.

The third cam phaser is located on the lowpressure exhaust valve cam and can be used to control the internal EGR rate, similar to the purpose of the exhaust cam phaser of a classical Dual Camphaser engine [12] .
The situation at load exchange top dead center (TDC) in charged operation points is also affected by the different valve configuration. The pressure inside the cylinder shortly before TDC is only slightly higher than ambient pressure due to the low pressure inside the LP exhaust manifold. Compared to a conventional turbocharged engine, the remaining EGR mass in the cylinder is lower. Additionally, as boost pressure builds on the intake side, a positive scavenging pressure ratio applies. This can be used for moderate scavenging at a wide engine speed range. However, the scavenging mass flow is lower as only one exhaust valve is available for the outflow.

As a result, the knock sensitivity of the engine is reduced, especially at high rpm, where conventional TC engines are not able to scavenge here.

\section{Engine speed limitation}

Very high engine speeds are challenging for the TwinAV system layout. On the one hand, the event length of the exhaust cam timing is comparatively short, which leads to high valve accelerations especially at high rpm. On the other hand the exhaust mass has to flow through only one exhaust valve. Thus, the flow losses will increase at high rpm. This situation leads to one important question for the simulation study - if there is still an advantage at $5000 \mathrm{rpm}$ against conventional turbocharging.

\section{Cylinder head layout}

A classical cylinder head layout comes with slightly larger diameter intake valves than exhaust valves to reduce the flow losses. Especially at the intake side, as it has a bigger impact to volumetric 
efficiency and thus engine power output, particularly for N/A engines.

However, turbocharged engines are not only limited by volumetric efficiency. The boost pressure can compensate for a slightly decreased volumetric efficiency. The power limitation is more defined by turbocharger speed, exhaust backpressure and temperature.

Thus, an engine equipped with TwinAV could have even-sized valves on intake and exhaust side. $A$ slightly larger exhaust valve diameter could compensate partly the increasing flow losses, when the residual exhaust gas is outflowing though only one exhaust valve.

Considering that scavenging is not very efficient on a 4-valve cylinder head when compared to a 2stroke engine as a high fraction of fresh gas is directly shortcut into the exhaust. High scavenging mass is required to remove the residual exhaust gas from the combustion chamber. The TwinAV concept with one opened exhaust valve during the load exchange TDC slightly improves this situation. However. it cannot reach the scavenging efficiency of a 2-stroke engine. Nonetheless, additional wedge-shaped masking can be applied as shown in figure 6. This avoids the shortcut between the LP exhaust valve and the neighboring intake valve and forces the flow (at small valve lift) to go over the surface of the closed HP valve. This asymmetry also results in a small swirl.

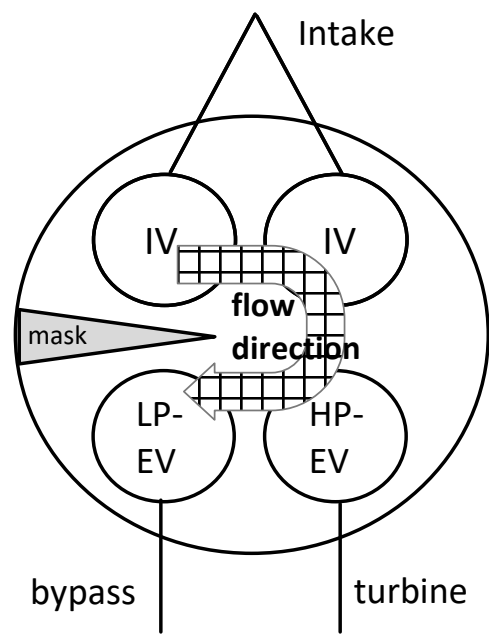

Figure 6: Proposed geometry of TwinAV optimized cylinder head

However, such a cylinder head is seen as a potential outlook for a second generation. In this first concept study, this is not considered to keep the similarity to the base engine as high as possible.

\section{Method - Simulation study}

Based on the principals of TwinAV, a parameter study was performed. Here, a known existing turbocharged engine was modeled within the 1D simulation software SimEngine [13], which is comparable to the GT suite [14]. The base engine is a 2.2 liter 4-cylinder direct injection TC engine with peak power of $195 \mathrm{~kW}$. Its brake specific maximum pressure (bmep) is 21.5 bar.

The simulation of the base engine fits well with test bed measurements. Especially in the case of indicated efficiency, calculated exhaust gas back pressure and knock limit, which is a result of the calculation by [15], good fitting to the behavior on the engine test bed was observed.

Based on that fitted engine model, the following modifications were performed to simulate the TwinAV system: 


\section{Expected behavior}

Split of the parallel opening exhaust cams to individual cam timing with following parameters:

- $\quad 1^{\text {st }}$ high pressure (HP) exhaust valve timing to $110^{\circ} \mathrm{CA}$, typically opening $50^{\circ}$ before BDC and closing $60^{\circ}$ after BDC

- $\quad 2^{\text {nd }}$ low pressure (LP) exhaust valve timing to $172^{\circ} \mathrm{CA}$, typically opening at BDC and closing $5-10^{\circ}$ before TDC

- Maximum lift of exhaust valve limited to $8 \mathrm{~mm}$ according to short event length

- Intake event length to $180^{\circ} \mathrm{CA}$ in base scenario, with tendency to early intake valve closing

- A cam phasing of up to $20^{\circ} \mathrm{CA}$ in positive and negative direction is considered depending on the operating point

- Reduction of turbine mass flow coefficient by $35 \%$ with an unchanged compressor wheel geometry

- The start of combustion (related to ignition angle) is shifted in a way to get a comparable knock probability

- Fuel enrichment changes, due to varying exhaust gas temperatures, are not considered. It is assumed, that an integrated exhaust manifold will overcompensate the temperature increase in the HP exhaust line.

The previously discussed modifications on geometry of the cylinder head such as masking were not considered within this simulation study.

In order to compare the full load application, a constant brake torque is controlled in, independent from boost pressure or other concept specific boundaries. To run those measurements on a test bed, a control system like [16] could be used.
As the TwinAV concept promised to reduce load exchange work in the operation range, where a turbocharger produces backpressure, it is expected to have high efficiency increasing potential in particular at full load. In addition, the reduced absolute cylinder charge during load exchange top dead center (TDC) potentially lead to beneficial behavior regarding the knock limitation.

At very low engine speeds, it is expected, that scavenging as well as sufficient boost pressure should still be possible, even with only $80 \%$ of exhaust mass flowing through the turbine. The smaller turbine should overcome this penalty and a comparable low-end-torque is likely achievable.

At very high engine speeds the benefit of this concept is reduced, due to the reduced valve cross section of only one exhaust valve. Especially as the exhaust valve lift was limited to $8 \mathrm{~mm}$ with respect to maximum valve acceleration at the smaller event length of $110^{\circ} \mathrm{CA}$. Regarding these expected limitations, the maximum speed of the simulation was set to $5500 \mathrm{rpm}$.

As there is very low backpressure at part load, it is expected, that there will be no significant efficiency gain in part load operation. Therefore, the simulation study is starting at an imep of 9 bar and goes up to 25 bar.

Regarding the expected higher backpressure at the HP exhaust valve, it is possible, that the exhaust temperatures in the HP exhaust manifold may be increased in comparison to the base engine, which will lead to higher enrichment demand for component protection. This effect is not considered in the shown diagrams. However, if an integrated 
exhaust manifold is used to separate both exhaust lines, its cooling effect may overcompensate.

\section{Results}

At first, a variation of engine speed at full load conditions was performed. Looking at the direct comparison between both variants over the simulated engine speed range of 1500 to 5500 rpm, an increasing efficiency gain over engine speed is apparent.

The reason for this can be found in the load exchange work of the base engine. At first, the gain of load exchange work of the TwinAV concept is 0.6 bar at $2000 \mathrm{rpm}$ and continuously decreases due to flow losses until -1.2 bar, see second diagram in figure 7. However, the exhaust backpressure of the base engine also increases over speed. As the exhaust backpressure is more than 3 bar absolute at $5500 \mathrm{rpm}$, the balance is much more negative than the balance of the TwinAV system. As a result, the load exchange imep difference remains at approximately 1.0 bar.

As expected, the lower absolute cylinder pressure at load exchange TDC leads to reduced internal EGR mass and temperature over the whole operation range, which further leads to a constant gain in knock limitation. The difference in the achievable peak pressure position is between 1 and $4^{\circ} \mathrm{CA}$ as it can be seen in the third diagram of figure 7 .

The simulation results show that there is a higher exhaust gas temperature at the HP exhaust line of $\sim 100 \mathrm{~K}$, which requires countermeasures such as additional enrichment or usage of an integrated exhaust manifold.
However, the temperature rise at $5500 \mathrm{rpm}$ is smaller than at lower engine speeds. The reason for this is, that although, the turbine is smaller, the difference in backpressure at $5500 \mathrm{rpm}$ is not much higher with TwinAV. The earlier combustion center also helps to limit the exhaust temperature in this scenario. The exhaust temperature increase correlates with the backpressure level, which is typically higher in the HP exhaust line. Downstream turbine and also inside the LP exhaust line, the exhaust temperature remains at a comfortable low temperature level. Therefore, component protection will only be necessary for turbine protection.

Both simulations have been carried out with the same $A / F$ ratio, so that an effect of enrichment for component protection is not considered. Especially regarding the low-end-torque of $2000 \mathrm{rpm}$, where TwinAV would need enrichment, the thermodynamic benefit of at least $4 \%$ load exchange imep gain would be nullified.

Figure 8 splits up the sources of efficiency gains. It can be seen, that a slightly increasing fraction of efficiency gain at full load is caused by the load exchange work, which reflects the principle idea of the TwinAV concept. A further fraction, not shown as separate bar, is based on the shifted knock border, which is the result of less residual gas fraction on one hand and less total air charge on the other hand. 

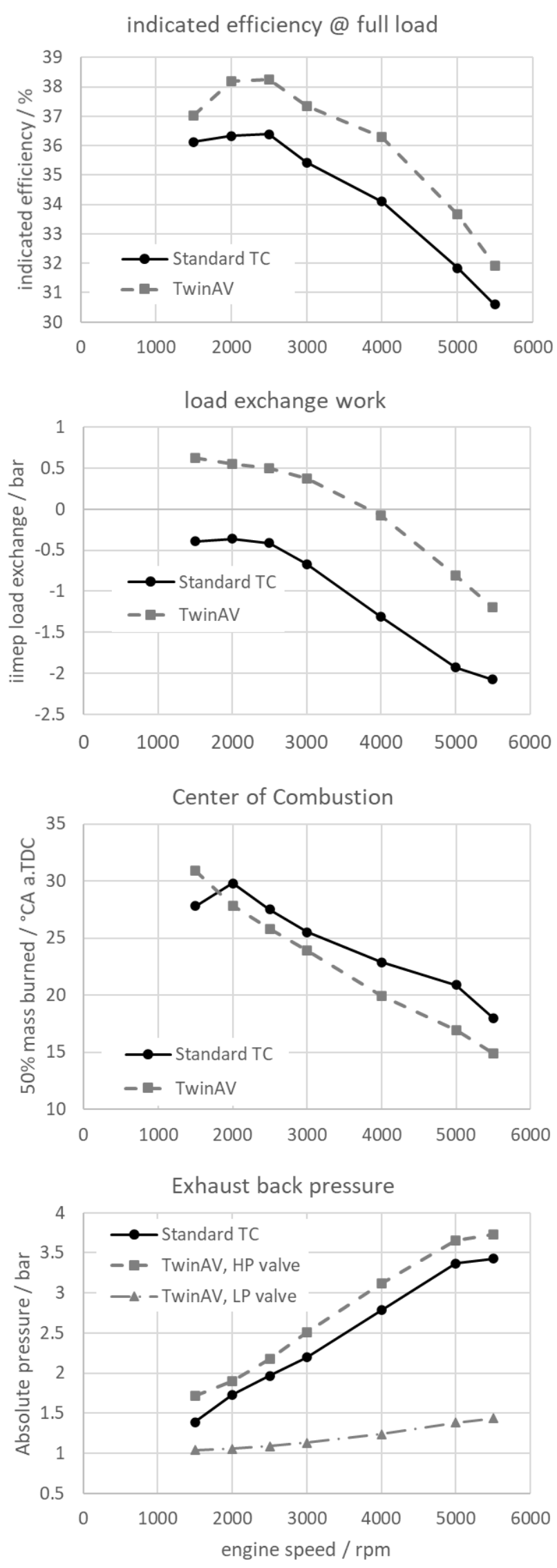

Figure 7: full load variation of TwinAV and base engine

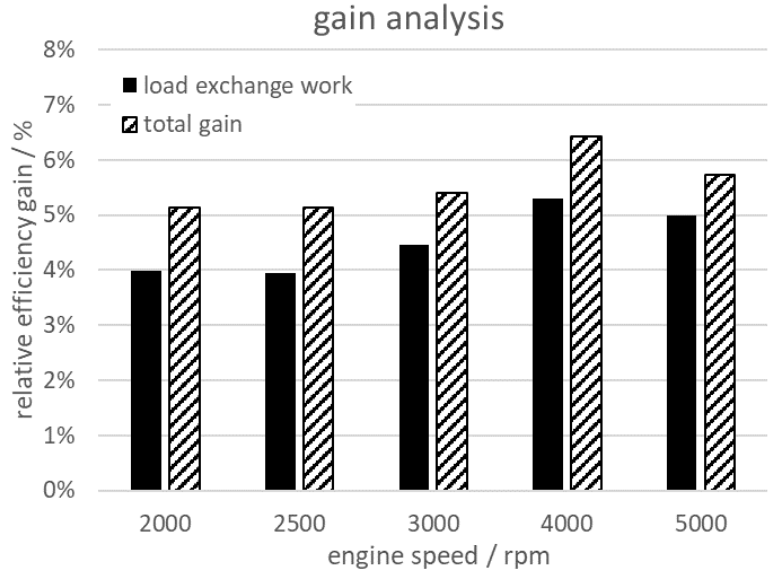

Figure 8: gain analysis of full load variation

The second variation was a load intersection performed at a constant engine speed of $2500 \mathrm{rpm}$.

Looking at the curves in figure 9, it can be noted, that the combined imep and boost pressure increment leads to an increasing load exchange work gain of the TwinAV engine, whereas the base engine shows an almost constant loss of $\sim 0$.3bar. The reason for this loss is the increasing exhaust backpressure, parallel to the increasing boost pressure. Due to additional flow losses, the imep measured at the piston is $0.3 \mathrm{bar}$. Even at 9 bar imep, there is still a small gain with the TwinAV concept visible. This is based on two reasons: a) As the intake cam closes before BDC, the volumetric efficiency of the engine is smaller than one, thus still a small boost pressure exits, b) the overall mass flow of the TC base engine is already high enough to have a small exhaust backpressure, even with opened waste gate. Also the knock behavior at the part load behaves as expected. In part load operation up to 12 bar imep, there is no knock limitation on both engines. With higher loads, the benefit of the TwinAV increases parallel with an increasing knock limitation and reaches a delta of up to $3^{\circ} \mathrm{CA}$, which was already observed at full load. 


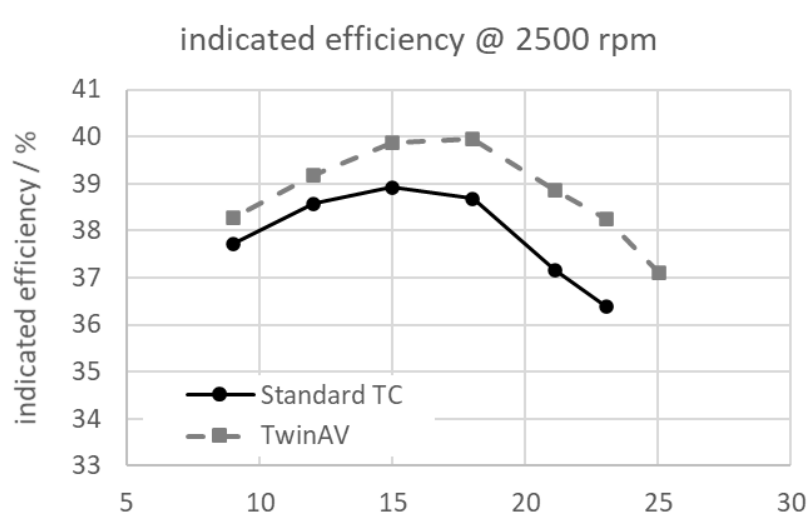

load exchange work
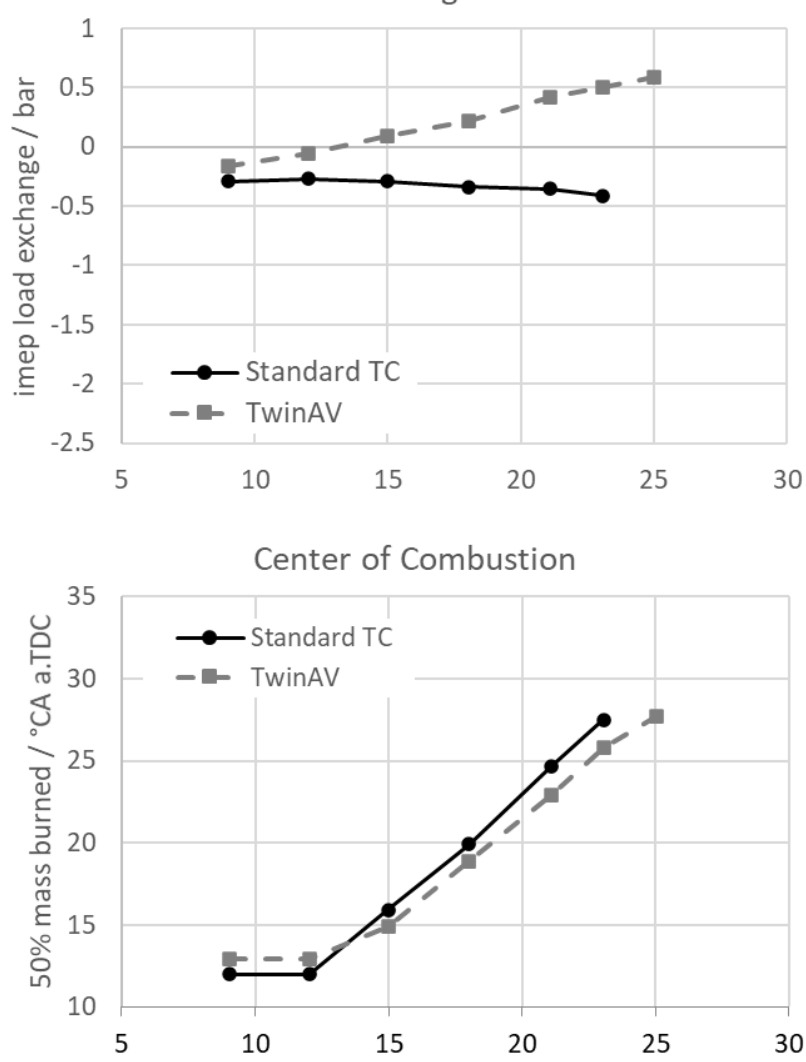

Exhaust back pressure

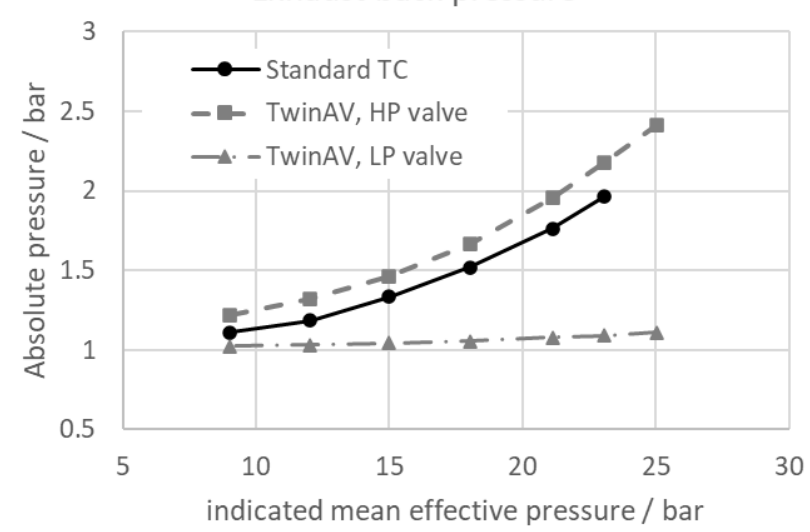

Figure 9: Load intersection at 2500 rpm
When looking at the part load gain analysis in figure 10 , it can be noted, that at 9 to 15 bar imep, where almost no knock limitation is present, the total gain in efficiency almost equals to the load exchange gain. A small difference occurs as the calculation of load exchange gain just considers the work of the piston between BDC and BDC in the load exchange loop, but small differences also occur in the high pressure loop close to BDC.

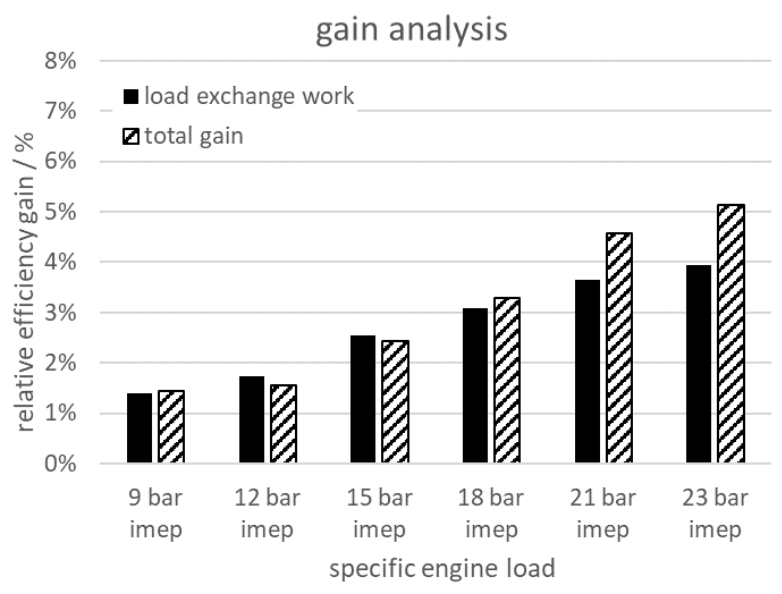

Figure 10: gain analysis of load intersection

\section{Analysis of $\mathrm{p}$-v-diagram}

The best comparability of conventional turbocharging with TwinAV can be noted, when comparing a constant air charge at the same engine speed. In this example a comparison is shown at $2500 \mathrm{rpm}$ in figure 11 . We can see a similar boost pressure during the intake stroke for both variants. When entering the compression stroke, both pressure curves are exactly on top of each other.

The difference in exhaust stroke can be seen when the exhaust valve opens. The conventional turbocharged variant purges the cylinder to approximately 2 bar and the pressure remains at this level. The TwinAV variant first purges the cylinder to 2.5 bar, where a saddle point in the pressure curve can be observed. After switching to the LP exhaust valve, the pressure further drops to 
1.2 bar. Starting from that point, there is a large gain of load exchange work. At the very left end of the $p$-V-diagram, it can be understood, that perfect scavenging conditions lead to a reduced knock behavior of the combustion.

As the load exchange efficiency of the TwinAV system is higher, the imep output is $6 \%$ higher in this example. When comparing an operation point with same imep or clutch torque, less air mass is needed, which additionally improves the effect of the reduced knock sensitivity.

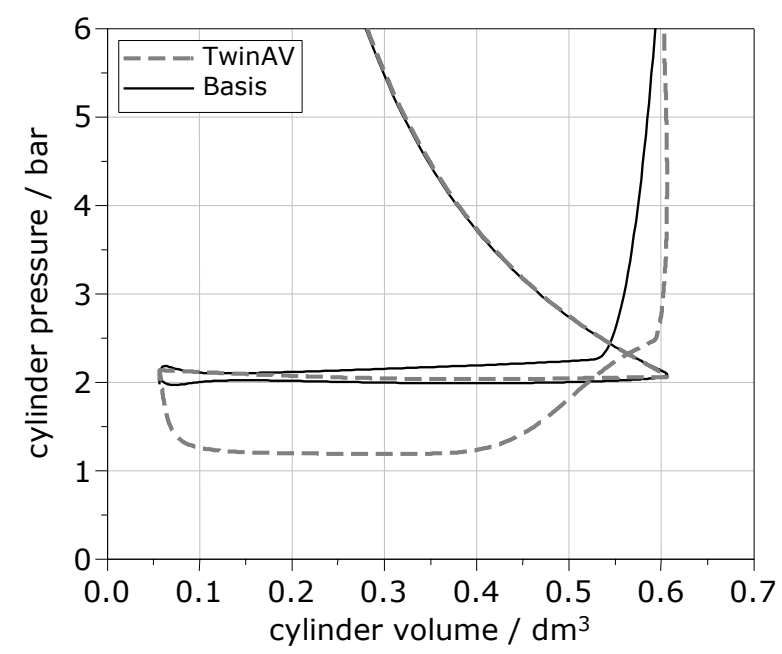

Figure 11: $p$-V-Diagram near optimum operation point, TwinAV and conventional turbocharging

When looking at the operation point $2500 \mathrm{rpm} / 12$ bar imep (figure 12), which is part-load at nearly N/A operation for the conventional turbocharged variant, due to the small backpressure upstream turbocharger, even with opened waste gate, a small negative contribution of the load exchange loop can be observed. With the TwinAV variant, the pressure for intake and exhaust stroke are almost the same, both slightly above environment ( 1.1 bar abs.). A small advantage against the wastegate-based turbocharging variant remains as no wastegate induced backpressure occurs.

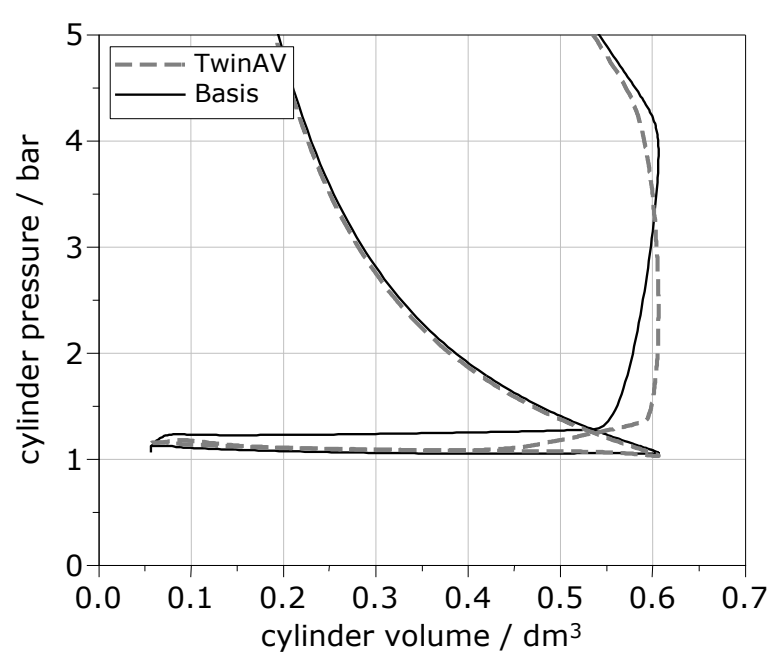

Figure 12: $\mathrm{p}-\mathrm{V}$-Diagram at $2500 \mathrm{rpm} / 12 \mathrm{bar}$ operation, TwinAV and conventional turbocharging

How do the increased flow losses at high rpm influence the system - It is demonstrated in figure 13 , where the simulation is performed for full load at $5000 \mathrm{rpm}$ and an imep of $21 \mathrm{bar}$. The air charge of the TwinAV system is lower to achieve the same imep. In both pressure curves it can be seen, that the static exhaust backpressure is very high (for TwinAV variant in HP phase) and much above the intake pressure level.

Although the flow losses are remarkably high, the transition from HP to LP exhaust valve can still be separated for the TwinAV variant. Due to the flow losses, the pressure never drops to environment pressure, but it drops much lower than the static backpressure of the conventional variant, whereby a small advantage in load exchange work remains. Although, while no scavenging is possible anymore, the lower absolute pressure at the end of exhaust in the left corner of the $p$-V-diagram in figure13 leads to a reduced knock sensitivity again. However, due to the flow limitations, the full load operating point shown in figure 13 appears to be the absolute full load. 


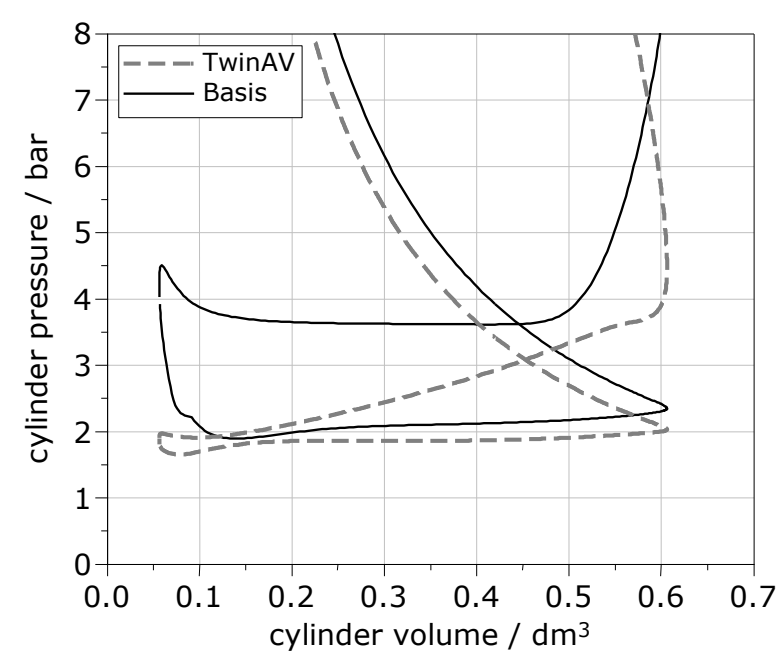

Figure 13: $p-V-D i a g r a m$ at 5000 rpm full load operation, TwinA $\mathrm{V}$ and conventional turbocharging

\section{Steady-state optimization}

For steady-state operation, assuming only a limited engine speed range, further modifications have been considered and simulated. Considering a maximum engine speed of $3000 \mathrm{rpm}$ in this scenario, even smaller cam events are selected:

- Intake cam $135^{\circ} \mathrm{CA}$

- HP Exhaust cam $95^{\circ} \mathrm{CA}$

- LP Exhaust cam $155^{\circ} \mathrm{CA}$

With this shortened event lengths and within a limited engine speed range, a better pressure handover from HP to LP is possible and on the intake side, thus additional usage of Miller-effect is possible.

Expecting, that the optimum efficiency will be in the operation range of $3000 \mathrm{rpm} / 20$ bar imep, cam phasing variants were performed to find an optimum operation point. The resulting $p-v$ diagram is shown in figure 14. A direct comparison with figure 11 shows that the transition from HP to LP valve could be achieved faster, which leads to an earlier decreasing cylinder pressure after BDC. Additionally, the excessive generated power at the turbine is used to produce a higher boost pressure. This boost pressure enhances the load exchange loop, but is not used for more air charge as the intake valve closes before BDC due to Miller cam strategy. The result is an indicated efficiency of $41.9 \%$, with a base scenario of $38.1 \%$. This is a relative improvement of $10 \%$ under best-case conditions.

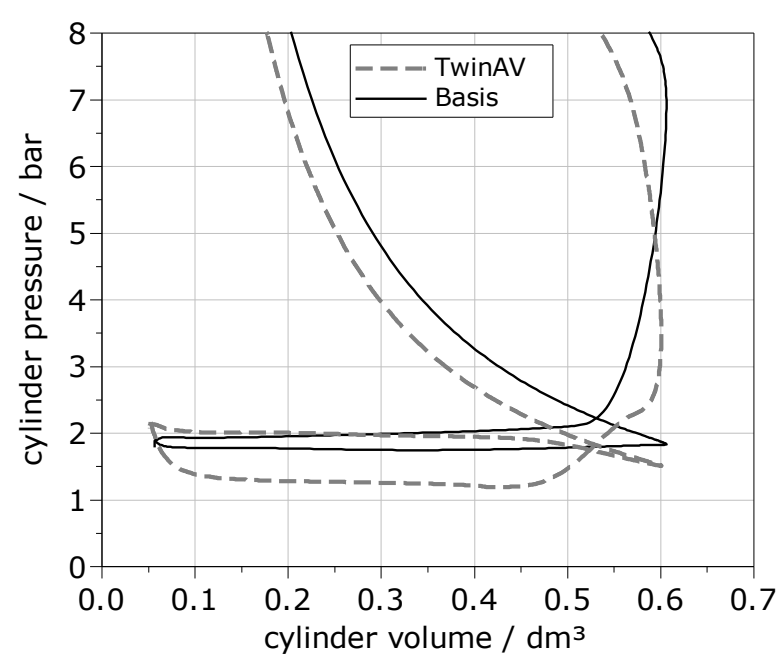

Figure 14: $p$-V-Diagram at steady-state optimized operation point 3000 rpm / 20 bar imep.

\section{Conclusion / Discussion}

The idea of turbocharging with different exhaust valve configuration TwinAV shows potential for efficiency improvement by reduction of the effective exhaust backpressure.

With this first simulation study, the thermodynamic properties of the TwinAV concept were analyzed and the potential for $\mathrm{CO}_{2}$ reduction was investigated. Depending on the cam-timing event length, the concept can be used either for invehicle application or steady-state operation, where up to 6.4 or $10 \%$ steady-state optimized efficiency gain has been calculated by the 1D simulation. The major contribution is achieved within the load exchange loop, and further improvements are the result of reduced knock sensitivity due to less internal EGR. It is important 
to note that this result was achieved without a change of the exhaust after treatment concept. All emission standards can still be met with stoichiometric operation.

However, as the TwinAV concept does need a design change of the cylinder head, it cannot be adapted to existing engines. But for serial production the design change of the cylinder head is feasible. A third cam phaser would be the most expensive additional part. The relation of additional cost and efficiency gain seems very attractive, if the engine is operated mainly at $>10$ imep.

\section{List of abbreviations}

$\begin{array}{ll}\text { Imep } & \text { indicated mean effective pressure } \\ \text { Bmep } & \text { brake mean effective presusre } \\ \text { BDC } & \text { Bottom Dead Centre } \\ \text { TDC } & \text { Top Dead Centre } \\ \text { CA } & \text { crank angle } \\ \text { LP } & \text { Low pressure (exhaust valve) } \\ \text { HP } & \text { High pressure (exhaust valve) } \\ \text { EV } & \text { exhaust valve } \\ \text { IV } & \text { intake valve } \\ \text { A/F } & \text { Air to fuel ratio } \\ \lambda & \text { inverse relative A/F ratio } \\ \text { EGR } & \text { Exhaust gas recirculation }\end{array}$

\section{Acknowledgment}

This potential analysis was funded internal by the start-up gofficient and its founder. There was no governmental or research funding so far. For further analysis research funding as well as commercial project requests are welcome. 


\section{Bibliography}

[1] Heywood, J. B. (Ed.): Internal combustion engine fundamentals. New York: McGrawHill.

[2] Pischinger, Stefan (Ed.) (2007): Vorlesungsumdruck VK I+II. RWTH Aachen.

[3] Gotter A.; Gotter A. (2007): Effiziente Energiewandlungsmaschine durch kombinierte Brennkraftmaschine mit Dampfprozess. Patent application DE102007038073.0.

[4] Gotter, A.; Küpfer, E. (2010): EFFICIENCY IMPROVEMENT OF INTERNAL COMBUSTION ENGINES BY WASTE HEAT RECOVERY WITH RANKINE CYCLE AND AN ADVANCED TURBOCHARGING PRINCIPLE. In: ICSAT Conference 2010. Ingolstadt.

[5] Freymann, Raymond; Ringler, Jürgen; Seifert, Marco; Horst, Tilmann (2012): Der Turbosteamer der Zweiten Generation. In MTZ - Motortechnische Zeitschrift 73 (2), pp. 114-119. DOI: 10.1365/s35146-0120245-1.

[6] Meli M. (2019): Konzeptevaluation einer regenerativen

Abgasenergierückgewinnung mittels Hochdruck-Dampfdirekteinblasung. Master thesis RWTH Aachen.

[7] Gotter A.; Gotter A. (2008): Internal combustion engine for motor vehicle, comprises charging device, which has compressor. Patent application DE102008056111A1.

[8] In, Byung Deok; Lee, Ki Hyung (2016): A study of a thermoelectric generator applied to a diesel engine. In Proceedings of the Institution of Mechanical Engineers, Part D: Journal of Automobile Engineering
230 (1), pp. 133-143. DOI:

10.1177/0954407015576440.

[9] Habermann, K. et al (2005):

Ventiltriebsvariabilitäten für aufgeladene

Ottomotoren. In : 10. Aufladetechnische

Konferenz. Dresden.

[10] Knecht A., Pohl D., Hannibal W. (2007):

Vane-Cam. Nockenwellenversteller mit neuen Funktionalitäten. In MTZ -

Motortechnische Zeitschrift 68 (1), pp. 3037.

[11] Schneider F., Lettmann M. (2007):

MAHLE CamInCam, die neue Lösung für variable Ventilsteuerzeiten. In : 16

Aachener Kolloquium Fahrzeug- und Motorentechnik. Aachen.

[12] Landerl, Christian; Mattes, Wolfgang; Rülicke, Markus; Durst, Bodo (2015): Der neue Reihensechszylinder-Ottomotor von BMW. In MTZ - Motortechnische Zeitschrift 76 (10), pp. 50-59. DOI: 10.1007/s35146-015-0090-0.

[13] Gotter, A. (2019): SimEngine Documentation. Edited by gofficient UG. Available online at http://www.gotter.de/download/gofficient Marketing_SimEngineThermo.pdf.

[14] Gamma Technologies LLC.: (Ed.): GTSUITE Overview. Available online at https://www.gtisoft.com/gt-suite/gt-suiteoverview/.

[15] Douaud, A. M.; Eyzat, P.: Four-OctaneNumber Method for Predicting the AntiKnock Behavior of Fuels and Engines. In: SAE Technical Paper.

[16] Gotter, Andreas (2009):

Brennraumdruckbasierte Motorsteuerung für Ottomotoren. Lichtenberg: HarlandMedia. ISBN: 978-3-938363-55-3, Dissertation RWTH Aachen 